\title{
Manisa İli Demirci İlçesinde Yetiştirilen Badem Çeşitlerinin Performanslarının Belirlenmesi
}

\section{Nihal ACARSOY BİLGIN}

Ege Üniversitesi Ziraat Fakültesi Bahçe Bitkileri Bölümü Bornova / İzmir

https://orcid.org/0000-0002-5018-6347

凹: nihalacarsoy@yahoo.com

\section{ÖZET}

Sert kabuklu meyveler grubunda üretim değeri yüksek olan badem, diyet ürünü olarak beslenmede önemli bir yere sahiptir. Ekolojiye uyum sağlayan çeşitlerde, düzenli kültürel uygulamalar sayesinde istenilen verim ve kaliteye ulaşmak mümkün olabilmektedir. Tesadüf blokları deneme desenine göre yürütülen bu çalışmada, Demirci/Manisa ekolojisinde yetiştirilen Nonpareil, Ferragnes, Ferrastar ve Texas badem çeşitlerinin fenolojik ve pomolojik özellikleri (meyve ağırlığı ve boyutları, kabuk kalınlığı, çift iç oranı ve renk) ile verimin ortaya konması amaçlanmıştır. İncelenen çeşitlerde çiçeklenme Martın ikinci yarısında olurken, hasat Ağustos-Eylül döneminde yapılmıştır. Kabuklu ve iç badem boyutları, renk parametreleri, çift iç oranı ve verim çeşitlere göre önemli farklılıklar göstermiştir. Buna göre, Ferrastar çeşidinde kabuklu meyve ağırlığı $(4.14 \mathrm{~g})$ ve kabuk kalınlığı $(3.21 \mathrm{~mm})$ yüksek, Nonpareil çeşidinde düşük bulunmuştur (1.95 g ve $1.79 \mathrm{~mm}$ ). En yüksek çift iç oranı ve verim sırasıyla Texas ve Ferragnes çeşitlerinde saptanmıştır. Çeşitler, bölge ekolojisine uyum sağlamış olup Nonpareil çeşidi ön plana çıkmıştır.

\section{Araştırma Makalesi}

Makale Tarihçesi

Geliş Tarihi : 25.05 .2019

Kabul Tarihi ：22.08.2019

\section{Anahtar Kelimeler \\ Amygdalus communis \\ Yetiştiricilik \\ Adaptasyon \\ Kalite \\ Verim}

\section{Determination of Performance of Almond Varieties Grown in Demirci District of Manisa Province}

\section{ABSTRACT}

Almonds, a hard-shelled nut fruit species, have an important role in nutrition as a dietary product. Optimum yield and quality can be achieved through regular cultural practices and preferring ecologically fitted varieties. This study was conducted as a randomized block design in Demirci/Manisa ecologic conditions. Aim of this study was to reveal phenological and pomological characteristics (fruit weight and size, shell thickness, double kernel ratio and color) and yield of Nonpareil, Ferragnes, Ferrastar and Texas almond varieties. Almond varieties were bloomed in the second half of March, while the fruits were harvested in August-September period. Fruit and kernel dimensions, color parameters, double kernel ratio and yields showed significant differences among varieties. Accordingly, the fruit weight $(4.14 \mathrm{~g})$ and the shell thickness $(3.21 \mathrm{~mm})$ were high in the Ferrastar cultivar, whereas these values were low in the Nonpareil variety (1.95 $\mathrm{g}$ and $1.79 \mathrm{~mm}$ ). The highest double kernel ratio and yield were determined in Texas and Ferragnes cultivars, respectively. Varieties, in general, had adapted to the ecology of the region. However, Nonpareil variety has come to the fore.

\section{Research Article}

$\begin{array}{ll}\text { Article History } \\ \text { Received } & : 25.05 .2019 \\ \text { Accepted } & : 22.08 .2019\end{array}$

Keywords
Amygdalus communis
Cultivation
Adaptation
Quality
Yield

Yield

To Cite : Acarsoy Bilgin N 2020. Manisa İli Demirci İlçesinde Yetiştirilen Badem Ceşitlerinin Performanslarının Belirlenmesi. KSÜ Tarım ve Doğa Derg 23 (1): 44-48. DOI: 10.18016/ ksutarimdoga.vi.570062.

\section{GİŖ̧̇}

Anavatanı Orta ve Batı Asya olan badem, dünyada geniş bir alana yayılmış olup ülkemizin birçok bölgesinde yetiştirilen sert kabuklu bir meyve türüdür (Dokuzoğuz ve Gülcan, 1973; Küden ve Küden, 2000). Türkiye, önemli üretici ülkeler arasında yer almaktadır. Dünya'da 2016 yılında, 3.214.303 ton olan toplam üretimde ülkemizin payı 85.000 tondur (Anonymous, 2018). Üretim yoğunluğu bakımından Ege Bölgesi'ni Akdeniz, Marmara ve Güneydoğu Anadolu Bölgeleri izlemektedir (Anonim, 2018).

Badem protein, vitamin, yağ asitleri, makro-mikro 
besin elementleri ve biyoaktif içeriği dolayısıyla diyet programlarının önemli bir yapı taşını oluşturmaktadır (Şen ve Karadeniz, 2015; Şimsek, 2016). Farklı tüketim şekilleri olan badem; çerez, şekerleme, çikolata, pasta endüstrisinde, badem yağı olarak kozmetik ve ilaç endüstrisinde de yoğun olarak kullanılmaktadır. Ekonomik açıdan değer taşıması ve muhafaza kolaylığı, bu meyve türüne ilginin giderek artmasına yol açmaktadır. Diğer taraftan, günümüzde özellikle hazine ve bozuk orman arazilerinde, özel ağaçlandırma teşviklerinde yer alması nedeniyle kırsal ekonominin canlanmasına katkı sağlaması açısından da dikkat çekmektedir (Erdoğan, 2016).

Yetiştiricilik genellikle, karışık bahçeler, doğada tohumdan meydana gelmiş ağaçlar ve sınır ağacı şeklinde yapılmaktadır. Bu durum, doğru ve düzenli kültürel uygulamalar yapılmaması nedeniyle pazar taleplerine uygun homojen kalitede ürün elde edilememesine neden olmaktadır. Bilindiği üzere, yüksek verim ve kaliteye, standart çeşitlerle tesis edilen kapama meyve bahçeleri ile ulaşılabilmektedir. Üretim alanları, tüketici talebine bağlı olarak artış göstermektedir. Meyveciliğin zor ve pahalı bir yatırım olması dolayısıyla yeni yetiştiricilik alanlarında çeşitlerinin performanslarının belirlenmesi önem taşımaktadır. $\mathrm{Bu}$ bağlamda, değişik ekolojik koşullardaki badem çeşitlerinde yürütülen çok sayıda adaptasyon, seleksiyon ile kalite ve verimin iyileştirilmesine yönelik çalışmalarda kabuklu ve iç bademin boyutları, ağırlığı, renk, iç randımanı, çift badem oluşturma eğilimi ve verim gibi özellikler incelenmektedir (Akçalı ve Uzun, 2016; Aslan, 2015; Imani ve Shamili, 2018; Milatovic ve ark., 2017).

Badem üretimi bakımından ilk sırada bulunan Ege Bölgesi'nde yer alan Manisa ilinde 2018 yılında 5800 ton kabuklu badem üretimi gerçekleşmiş̧tir (Anonim, 2018). Verimlilik açısından çeşitlerin yetiştirildiği bölgeye uyumu birinci sırada önem taşımaktadır. İlkbaharda erken çiçeklenmesi dolayısıyla geç don riski olan bu türde, Ferragnes, Ferrastar ve Texas gibi geç çiçeklenen ve kabuğu elle kolay kırılan Nonpareil çeşitleri ile son zamanlarda yeni kapama bahçelerin kurulduğu dikkat çekmektedir. Bu durum, çeşitlerin bölgeye adaptasyonunu belirlenmesini gerekli kılmaktadır. Yukarıdaki açıklamalar ışı̆̆ında planlanan bu çalışmada, badem çeşitlerin Manisa ili Demirci ilçesi ekolojik koşullarında verim ve bazı meyve özellikleri açısından ekonomik anlamda yetiştiriciliğinin mümkün olup olmadığının tespiti amaçlanmıştır. $\mathrm{Bu}$ sayede, çeşitlerin yetiştiriciliğinin sürdürülebilirliği de ortaya konulabilecektir.

\section{MATERYAL ve METOT}

Bu çalışma, Demirci/Manisa'da üreticilere ait iki farklı bahçede 2018 yılında yürütülmüştür. Nonpareil, Texas, Ferragnes ve Ferrastar badem çeşitleri materyal olarak kullanılmıştır. Ağaçlar 7 yaşlı olup verim dönemindedir. Toprak isteği bakımından seçici olmayan bademde (Küden ve ark., 2014), Nonpareil ve Texas çeşitlerinin yetiştiği bahçenin toprak yapısının kinli tınll, hafif alkali kireçli, organik maddece iyi, fosfor ve potasyum miktarının yüksek olduğu belirlenmiştir. Buna karşılık, Ferragnes ve Ferrastar badem çeşitlerinin yetiştirildiği bahçenin toprak yapısının tınlı, hafif alkali, kireçli, organik maddece az, fosfor ve potasyum miktarının yüksek olduğu belirlenmiştir. Bahçelerde çiftlik gübresi, taban ve yaprak gübresinin yanı sıra düzenli kültürel uygulamalar ve sulama yapılmaktadır.

Fenolojik gözlemlerde çiçeklenme başlangıcı, tam çiçeklenme, yapraklanma, hasat ve yaprak dökümü zamanı belirlenmiştir. Hasat döneminde (Ağustos Eylül) her tekerrürden alınan 30 adet meyve örneği, kabuklarından ayrılarak gölgede kurulmuştur. Analizler Ege Üniversitesi Ziraat Fakültesi Bahçe Bitkileri Bölümü'nde yapılmıştır. Ortalama meyve ağırlığı ve iç ağırlığı için örnekler $0.01 \mathrm{~g}$ duyarlı elektronik terazide tartılmıştır. Kabuklu ve iç bademlerin eni (genişlik, yanak çapı), boyu (uzunluk), yüksekliği (kalınlık, sutur çapı) ve kabuk kalınlığı mm cinsinden 0.01 mm'ye duyarlı dijital kumpas yardımıyla ölçülmüştür. İç bademin rengi Minolta kolorimetresi (CR-400, Minolta Co, Japonya) ile CIE $L^{*}, a^{*}, b^{*}$ cinsinden okunmuştur. Elde edilen $a^{*}$ ve $b^{*}$ değerlerinden kroma $\left(\mathrm{C}^{*}=\left[\mathrm{a}^{*} 2+\mathrm{b}^{*} 2\right] 1 / 2\right)$, ve hue açısı $\left(\mathrm{h}^{\circ}=\tan -1\left[\mathrm{~b}^{*} / \mathrm{a}^{*}\right]\right)$ değeri hesaplanmıştır (McGuire, 1992).Verim kg ağaç-1,çift badem oranı ise \% olarak belirlenmiştir.

Tesadüf blokları deneme desenine göre, 3 tekerrürlü olarak planlanan çalışmada her tekerrür 3 ağaçtan oluşmaktadır. Elde edilen veriler SPSS 20 istatistik paket programı kullanılarak, One Way Anova ile $\mathrm{p} \leq 0,05$ önem derecesinde analizine tabi tutulmuştur. Çeşitler arasındaki farklılıklar Tukey testi ile ortaya konmuş olup sonuçlar harfli olarak gösterilmiştir.

\section{BULGULAR ve TARTIŞMA}

Fenolojik gözlemlere ilişkin veriler Çizelge 1'de izlenmektedir. İncelenen çeşitlerin, genel olarak, Şubat'ın ikinci yarısında çiçeklendiği belirlenmiştir. Nonpareil çeşidinin 16 Mart'ta tam çiçeklenme periyodunda olduğu gözlenirken, diğer çeşitlerde bu dönem yaklaşık 7-10 gün sonra kaydedilmiştir. Yapraklanma dönemine tam çiçeklenmeden 10 gün sonra ulaşılmış olup yapraklar Ekim ayının sonunda dökülmüştür. Nonpareil, diğer çeşitlere göre 1 ay kadar önce hasat edilmiştir. Bilindiği üzere, fenolojik veriler çeşit, lokasyon ve yıllara göre farklılık göstermektedir. $\mathrm{Bu}$ bağlamda, tam çiçeklenme zamanı, Şanlıurfa koşullarında Nonpareil, Texas ve Ferragnes çeşitlerinde Mart ortasında (Aslan, 2015), Erciyes dağı eteklerinde doğal florada bulunan badem tiplerinde ise 8-25 Mart olarak gözlenmiştir (Akçalı ve Uzun, 2016). 
İncelenen badem çeşitlerinin kabuklu ve iç ağırlıkları, kabuk kalınlığı, çift iç oranı ve verim değerleri Çizelge 2 'de yer almaktadır. İç badem ağırlığı hariç, çeşitlere bağlı olarak söz konusu özellikler bakımından istatistiksel farklılık ortaya çıkmıştır. Kabuklu meyve ağırlığı ve kabuk kalınlığı bakımından en yüksek (4.14 $\mathrm{g}$ ve $3.21 \mathrm{~mm})$ ve en düşük (3.21 g ve $1.79 \mathrm{~mm}$ ) değerler sırasıyla Ferrastar ve Nonpareil çeşitlerinde tespit edilmiştir. Her çeşit farklı istatistiksel grup oluşturmuştur. Çift iç oluşumu Ferragnes ve Ferrastar çeşitlerinde görülmezken, Nonpareil'de \%4 ve Texas'da $\% 11$ oranında saptanmıștır. En yüksek verim $15 \mathrm{~kg}$ ağaç-1 ile Ferragnes çeşidinden elde edilmiştir. Bunu $12 \mathrm{~kg}$ ağaç-1 ile aynı grupta yer alan Texas çeşidi izlemiştir.

Çizelge 1. Badem çeşitlerinde fenolojik gözlemler

Table 1. Phenological observations in almond varieties

\begin{tabular}{|c|c|c|c|c|c|}
\hline $\begin{array}{l}\text { Çesiit } \\
\text { Variety }\end{array}$ & $\begin{array}{l}\text { Ciçeklenme başlangicı } \\
\text { Start of blooming }\end{array}$ & $\begin{array}{l}\text { Tam çiçeklenme } \\
\text { Full bloom }\end{array}$ & $\begin{array}{l}\text { Yapraklanma } \\
\text { Foliation }\end{array}$ & Hasat (Har & $\begin{array}{c}\text { Yaprak dökümü } \\
\text { Defoliation }\end{array}$ \\
\hline Nonpare & 18 Şubat (February) & 16 Mart (March) & 25 Mart (March) & 05 Ağustos (Augz & 20 Ekim (October) \\
\hline Tex & lary) & (rch) & (rch) & $03 \mathrm{E}$ & ctober) \\
\hline Ferragnes & (February) & (March) & $\mathrm{n}$ (April) & $03 \mathrm{Ey}$ & $25 \operatorname{Ekim}$ (October) \\
\hline Ferrastar & 28 Şubat (February) & 25 Mart(March) & 05 Nisan (April) & 03 Eylül(September) & 25 Ekim (October $)$ \\
\hline
\end{tabular}

Çizelge 2. Badem çeşitlerinin bazı meyve özellikleri ve verim

Table 2. Some fruit characteristics and yield of almond varieties

\begin{tabular}{|l|c|c|c|c|c|}
\hline $\begin{array}{l}\text { Ceşit } \\
\text { Variety }\end{array}$ & $\begin{array}{c}\text { Kabuklu meyve } \\
\text { ağırlığ }(\mathrm{g}) \\
\text { Fruit weight }\end{array}$ & $\begin{array}{c}\text { İç badem } \\
\text { ağlrlığı }(\mathrm{g}) \\
\text { Kernel weight }\end{array}$ & $\begin{array}{c}\text { Kabuk kalınlığ } \\
(\mathrm{mm}) \\
\text { Shell thicknesS }\end{array}$ & $\begin{array}{c}\text { Cift iç oranı (\%) } \\
\text { Percent double } \\
\text { kernels }\end{array}$ & $\begin{array}{c}\text { Verim (kg ağaç-1) } \\
\text { Yield }\end{array}$ \\
\hline Nonpareil & $1.95 \pm 0.10 \mathrm{~d}$ & $1.06 \pm 0.00^{\text {ö.d.(ns) }}$ & $1.79 \pm 0.08 \mathrm{~d}$ & $4.00 \pm 0.58 \mathrm{~b}$ & $7.00 \pm 0.58 \mathrm{c}$ \\
\hline Texas & $2.49 \pm 0.75 \mathrm{c}$ & $1.10 \pm 0.12$ & $2.56 \pm 0.03 \mathrm{c}$ & $11.00 \pm 0.58 \mathrm{c}$ & $12.00 \pm 0.58 \mathrm{ab}$ \\
\hline Ferragnes & $3.19 \pm 0.08 \mathrm{~b}$ & $1.12 \pm 0.02$ & $2.81 \pm 0.04 \mathrm{~b}$ & $0.00 \pm 0.00 \mathrm{a}$ & $15.00 \pm 1.73 \mathrm{a}$ \\
\hline Ferrastar & $4.14 \pm 0.06 \mathrm{a}$ & $1.27 \pm 0.04$ & $3.21 \pm 0.05 \mathrm{a}$ & $0.00 \pm 0.00 \mathrm{a}$ & $10.00 \pm 0.58 \mathrm{bc}$ \\
\hline
\end{tabular}

Ortalamalar arasındaki farklılıklar Tukey testiyle $(\mathrm{P} \leq 0.05)$ belirlenmiştir. ö.d., önemli değil. Ortalama \pm Standart Hata

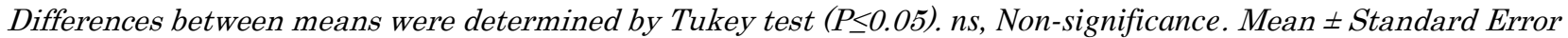

Çizelge 3’de görüldüğü üzere, kabuklu ve iç badem boyutlarının çeşitlere göre değişimi istatistiksel açıdan önem taşımaktadır. Kabuklu meyve boyutlarına ilişkin en yüksek değerler Ferrastar çeşidinde tespit edilmiştir. Söz konusu çeşit iç badem eni bakımından da $15.50 \mathrm{~mm}$ ile ilk sırada yer almıştır. İç badem boyutları meyve iriliğini belirlemesi dolayısıyla önemli bir kalite kriteridir. Badem boyu dikkate alındığında ise Ferragnes $(25.20 \mathrm{~mm})$, Ferrastar $(24.98 \mathrm{~mm})$ ve Nonpareil (24.67 $\mathrm{mm})$ çeşitleri aynı grubu oluştururken, Texas (21.56 $\mathrm{mm})$ diğer grupta bulunmaktadır. İç bademin yüksekliği $6.76 \mathrm{~mm}$ (Nonpareil) ve $8.05 \mathrm{~mm}$ (Texas) aralığında değişmiştir.

Çizelge 3. Badem çeşitlerinde kabuklu ve iç badem boyutları $(\mathrm{mm})$

Table 3. Fruit and kernel dimensions in almond varieties ( $\mathrm{mm}$ )

\begin{tabular}{|l|c|c|c|c|c|c|}
\hline $\begin{array}{l}\text { Ceşit } \\
\text { Variety }\end{array}$ & $\begin{array}{c}\text { Kabuklu en } \\
\text { Fruit width }\end{array}$ & $\begin{array}{c}\text { Kabuklu boy } \\
\text { Fruit length }\end{array}$ & $\begin{array}{c}\text { Kabuklu } \\
\text { yükseklik } \\
\text { Fruit height }\end{array}$ & $\begin{array}{l}\text { İç badem en } \\
\text { Kernel width }\end{array}$ & $\begin{array}{l}\text { İç badem boy } \\
\text { Kernel length }\end{array}$ & $\begin{array}{c}\text { İç badem } \\
\text { yükseklik } \\
\text { Kernel height }\end{array}$ \\
\hline Nonpareil & $21.15 \pm 0.35 \mathrm{~b}$ & $35.60 \pm 0.75 \mathrm{~b}$ & $14.20 \pm 0.54 \mathrm{~b}$ & $12.45 \pm 0.11 \mathrm{c}$ & $24.67 \pm 0.09 \mathrm{a}$ & $6.76 \pm 0.04 \mathrm{c}$ \\
\hline Texas & $20.81 \pm 0.22 \mathrm{~b}$ & $30.41 \pm 0.22 \mathrm{~d}$ & $16.09 \pm 0.00 \mathrm{a}$ & $12.32 \pm 0.16 \mathrm{c}$ & $21.56 \pm 0.20 \mathrm{~b}$ & $8.05 \pm 0.16 \mathrm{a}$ \\
\hline Ferragnes & $21.25 \pm 0.20 \mathrm{~b}$ & $33.19 \pm 0.35 \mathrm{c}$ & $14.92 \pm 0.03 \mathrm{ab}$ & $13.05 \pm 0.08 \mathrm{~b}$ & $25.20 \pm 0.22 \mathrm{a}$ & $7.63 \pm 0.09 \mathrm{a}$ \\
\hline Ferrastar & $25.31 \pm 0.07 \mathrm{a}$ & $39.63 \pm 0.23 \mathrm{a}$ & $16.18 \pm 0.28 \mathrm{a}$ & $15.50 \pm 0.06 \mathrm{a}$ & $24.98 \pm 0.12 \mathrm{a}$ & $7.19 \pm 0.04 \mathrm{~b}$ \\
\hline
\end{tabular}

Ortalamalar arasındaki farklılıklar Tukey testiyle $(\mathrm{P} \leq 0.05)$ belirlenmiştir. Ortalama \pm Standart Hata

Differences between means were determined by Tukey test ( $P \leq 0.05)$. Mean \pm Standard Error

Şanlıurfa koşullarında yapılan yetiştiricilikte, kabuklu meyve ağırlığı, kabuk kalınlığg ve çift iç oranı sirasıyla Nonpareil için $5.14 \mathrm{~g}, 3.35 \mathrm{~mm}, \% 3$, Texas için $3.29 \mathrm{~g}, 2.65 \mathrm{~mm}, \% 9$ ve Ferragnes için $5.27 \mathrm{~g}, 4.16 \mathrm{~mm}$, $\% 0$ olarak tespit edilmiştir (Aslan, 2015). Aynı ekolojide yürütülen farklı çalışmalarda, ağaç başına verim değerleri Nonpareil için $8.14 \mathrm{~kg}$ (Kaşka ve ark., 1994) ve Ferragnes için 2.18 kg (Kaşka ve ark., 1998) olarak belirlenmiştir. Ak ve Parlakcı (2018), tarafından bu lokasyonda, yürütülen diğer bir çalışmada, Ferragnes çeşidinin iç badem boyutları ve verim değerleri belirlenmiştir (boy $25.1 \mathrm{~mm}$, en 13.59 $\mathrm{mm}$, kalınlık $7.77 \mathrm{~mm}$, verim $8.22 \mathrm{~kg}$ ağaç-1). Yine aynı çeşit için, kabuklu meyve ağırlığı $3.5 \mathrm{~g}$, iç ağırlığı 1.5 $\mathrm{g}$, çift iç oluşumu $\% 0$ olarak belirtilirken, bu değerler sirasıyla Nonpareil çeşidinde, $2.1 \mathrm{~g}, 1.4 \mathrm{~g}, \% 20-25$ ve Texas çeşidinde, $3.0 \mathrm{~g}, \quad 1.5 \mathrm{~g}$ ve $\% 39$ olarak bildirilmektedir. Ayrica Ferragnes ve Nonpareil çeşitlerinde kabuklu (21, 36, 16 ve $19,33,12 \mathrm{~mm})$ ve iç 
badem $(13,29,8$ ve $13,25,8 \mathrm{~mm})$ boyutları da belirlenmiştir (Küden ve ark., 2014). Atatürk Bahçe Kültürleri Merkez Araştırma Enstitüsü badem koleksiyon parselinde yer alan, Ferrastar (4.65 g ve $1.53 \mathrm{~g})$, Ferragnes (4.18 g ve $1.60 \mathrm{~g}$ ) ve Nonpareil (2.65 g ve $1.35 \mathrm{~g}$ ) çeşitlerinin kabuklu ve iç badem ağırlıkları tespit edilmiştir (Akçay ve Tosun, 2005).

Fas ekolojik koşullarındaki benzer bir çalışmada, Ferragnes ve Texas çeşitlerinde kabuklu meyve ağırlığı 4.60 g ve 4.66 g, iç ağırlığı 1.43 g ve1.18 g, çift iç oranı $\% 0$ ve $\% 39$ olduğu ifade edilmektedir. Kabuklu meyve boyu $37.74 \mathrm{~mm}$ ve $27.37 \mathrm{~mm}$, eni $23.68 \mathrm{~mm}$ ve $19.84 \mathrm{~mm}$, kalınlığı $16.63 \mathrm{~mm}$ ve $17.25 \mathrm{~mm}$;iç bademin boyu $27.49 \mathrm{~mm}$ ve $20.14 \mathrm{~mm}$, eni $14.39 \mathrm{~mm}$ ve 12.79 $\mathrm{mm}$, kalınlığ $8.17 \mathrm{~mm}$ ve $9.94 \mathrm{~mm}$ olarak saptanmıştır (Hanine ve ark., 2016). Yine Fas'da 5 farklı lokasyonda yetiştirilen Ferragnes çeşidinde; kabuklu meyve ağırlığı $2.65-3.68 \mathrm{~g}$, boy $28.02-33.74 \mathrm{~mm}$, en $19.63-$ $22.68 \mathrm{~mm}$, kalınlık $13.83-15.04 \mathrm{~mm}$ arasında değişim göstermiştir. İç meyve ağırlığı $0.88-1.19 \mathrm{~g}$, boy 21.36 - $25.12 \mathrm{~mm}$, en $19.63-22.68 \mathrm{~mm}$, kalınlık $7.19-8.17$ mm, çift oran $\% 0$ - 12 sinırlarında tespit edilmiştir (Melhaoui ve ark., 2018).

Aynı çeşitlerle değişik lokasyonlarda yürütülen çalışmalarda incelenen özellikler bakımından farklılık görülmektedir. Bu durum, lokasyon, ağacın yaşı, ürün

Çizelge 4. Badem çeşitlerinin renk değerleri

Table 4. Color values of almond varieties

\begin{tabular}{|l|c|c|c|c|c|}
\hline Çeşit (Variety) & $\mathrm{L}^{*}$ & $\mathrm{a}^{*}$ & $\mathrm{~b}^{*}$ & $\mathrm{C}^{*}$ & $\mathrm{~h}^{\circ}$ \\
\hline Nonpareil & $58.13 \pm 0.58 \mathrm{a}$ & $16.14 \pm 0.46 \mathrm{~b}$ & $45.40 \pm 0.14 \mathrm{a}$ & $48.19 \pm 0.09 \mathrm{a}$ & $70.43 \pm 0.55 \mathrm{a}$ \\
\hline Texas & $45.36 \pm 0.58 \mathrm{~b}$ & $15.89 \pm 0.22 \mathrm{a}$ & $35.51 \pm 0.24 \mathrm{~b}$ & $38.90 \pm 0.31 \mathrm{c}$ & $65.90 \pm 0.18 \mathrm{~b}$ \\
\hline Ferragnes & $45.19 \pm 0.18 \mathrm{~b}$ & $18.90 \pm 0.26 \mathrm{a}$ & $37.37 \pm 0.66 \mathrm{~b}$ & $41.88 \pm 0.70 \mathrm{~b}$ & $63.17 \pm 0.11 \mathrm{c}$ \\
\hline Ferrastar & $43.08 \pm 0.16 \mathrm{~b}$ & $18.12 \pm 0.30 \mathrm{~b}$ & $36.40 \pm 0.51 \mathrm{~b}$ & $40.72 \pm 0.44 \mathrm{bc}$ & $63.58 \pm 0.55 \mathrm{c}$ \\
\hline
\end{tabular}

Ortalamalar arasındaki farklılıklar Tukey testiyle $(\mathrm{P} \leq 0.05)$ belirlenmiştir. Ortalama \pm Standart Hata

Differences between means were determined by Tukey test $(P \leq 0.05)$. Mean \pm Standard Error

\section{SONUÇ ve ÖNERILER}

Günümüzde, özellikle, sağlık açısından önemi giderek artan bu türde yürütülen çalışmada, irilik, açık renkli, çift iç oranının düşük ve kabuğunun ince olması dolayısıyla Nonpareil çeşidi ön plana çıkmıştır. Bu çeşitte oransal olarak meyve tutumu yüksek olmakla beraber kabuk ağırlı̆̆ının az olması nedeniyle verim diğer çeşitlere göre daha düşük olmaktadır. Bu durum, çeşit özelliğinin bir sonucu olarak ortaya çıkmaktadır. Ancak kilogramdaki adet miktarının fazla olması ve daha yüksek fiyatla satılması bölgede yetiştiriciliğinin yaygınlaşmasına yol açmaktadır. Doğru ve düzenli kültürel uygulamaların gerçekleştirilmesi durumunda, verim ve kalite özelliklerinin genel anlamda pazar talebine uygun nitelikte ürün elde edilebilmektedir. Bu durum, incelenen çeşitlerin ekolojiye uyum sağladığının bir göstergesi olarak değerlendirilebilmektedir. Standart çeşitlerle tesis edilen kapama bahçeler ile pazarın sürdürülebilirliği mümkün olabilmektedir. miktarı ve çevresel koşulların farklılığından kaynaklanabilmektedir (Akçay ve Tosun, 2005; Oğuz ve ark., 2011). Bademde önemli bir kalite kriteri olan çift iç oluşumu da, genetik ve çevresel faktörlere göre değişebilmektedir (Çelik ve Balta, 2011).

Tüm renk parametreleri bakımından çeşitler arasındaki farklılıklar önem taşımaktadır (Çizelge 4). L* değerinin yüksek olması bademin daha açık renkli olduğunun bir göstergesi olup 58.13 ile Nonpareil çeşidi iyi sonuç vermiştir. Kırmızı rengi gösteren $a^{*}$ değeri, genel olarak, düşük bulunmuştur. Bu değere göre, Ferragnes ve Texas çeşitleri aynı grupta yer almıştır. Sarı rengin varlığını ifade eden $b^{*}$ değeri 45.40 ile Nonpareil çeşidinde yüksek, 35.51 ile Texas çeşidinde düşük saptanmıştır. Renk doygunluğunu belirleyen kroma 48.19 ile Nonpareil çeşidinde yüksek tespit edilmiş olup parlaklığın arttığına işaret etmektedir. Renk tonunu belirleyen hue değeri 900'ye yaklaştıkça sarı rengi göstermekte olup Nonpareil çeşidi bu bakımdan diğer çeşitlere göre daha yüksek değere sahip olmuştur. Farklı amaçlara yönelik çalışmalarda badem (Valverde ve ark., 2006), findık (Lopes ve ark., 2016) ve kestane (Erdal, 2013) gibi meyve türlerinde de renk parametreleri ortaya konmuştur.

\section{TEŞEKKÜR}

Çalışmanın yürütülmesine olanak sağlayan Sayın Mehmet SEYMAN ve Sayın Murat NACAROĞLU'na sonsuz teşekkürler.

\section{Çıkar Çatışması Beyanı}

Makale yazarı herhangi bir çıkar çatışması olmadığını beyan ederler.

\section{KAYNAKLAR}

Ak BE, Parlakcı H 2018. Fruit Set, Yield and Some Quality Traits of Different Foreign Almond Cultivars Grown Sanlıurfa Province. Proceedings of the IX International Agricultural Symposium, Agrosym.

Akçalı E, Uzun A 2016. Erciyes Dağı Eteklerinden Seçilen Badem (Prunus amygdalus L.) Tiplerinde Bazı Fenolojik ve Pomolojik Özelliklerin Belirlenmesi. Akademik Ziraat Dergisi 5(2):63-68.

Akçay ME, Tosun İ 2005. Bazı Geç Çiçek Açan Yabancı 
Badem Çeşitlerinin Yalova Ekolojik Koşullarındaki Gelişme ve Verim Davranışları. Atatürk Üniv. Ziraat Fak. Derg. 36 (1):1-5.

Aslan R 2015. Bazı Yabancı Kökenli Badem Çeşitlerinin Şanlıurfa Koşullarında Fenolojik ve Pomolojik Özellikleri. Ordu Üniversitesi Fen Bilimleri Enstitüsü Bahçe Bitkileri Anabilim Dalı, Yüksek Lisans Tezi, $71 \mathrm{~s}$.

Anonim 2018. Türkiye İstatistik Kurumu. Bitkisel üretim istatistikleri.

Anonymous 2018. Food \& Agriculture Organization of the united nations (fao)

Çelik F, Balta MF 2011. Kernel Fatty Acid Composition of Turkish Almond (Prunus dulcis) Genotypes: A Regional Comparison. Journal of Food, Agriculture \& Environment, 9(1): 171-174.

Dokuzoğuz M, Gülcan R 1973. Ege Bölgesi Bademlerinin Seleksiyon Yoluyla Islahı ve Seçilmiş Tiplerin Adaptasyonu Üzerine Araştırmalar. Kesin rapor. TOAG TÜBİTAK, No:22.

Erdal E 2013. Kestanelerde (Castanea sativa Mill.) Hasat Öncesi ve Sonrası Dönemlerde Meyve Kalite Özelliklerinin Değişimi Üzerine Bir Araştırma. Adnan Menderes Üniversitesi, Fen Bilimleri Enstitüsü, Bahçe Bitkileri Anabilim Dalı, Yüksek Lisans Tezi, $67 \mathrm{~s}$.

Erdoğan V 2016. Hazine ve Bozuk Orman Arazilerinde Badem ve Ceviz Bahçesi Tesisleri. Bahçe Özel Say1: VII. Ulusal Bahçe Bitkileri Kongresi Bildirileri Cilt I: Meyvecilik. 242-247s.

Hanine H, Zinelabidine LH, Kodad O, Hssaini H, Haddioui A, Ennahli S 2016. Pomological, Phenotypical Diversity and Biochemical Characterization of Fortheen Almond Morphotypes from Morocco. Options Méditerranéennes, A, no. 119,- XVI GREMPA Meeting on Almonds and Pistachio

Imani A, Shamili M 2018. Almond Nut Weight Assessment by Stepwise Regression and Path Analysis. International Journal of Fruit Science, 18 (3): 338-343.

Kaşka N, Küden A, Küden AB 1994. Almond Production in Southerast Anatolia. Acta Hort: 373: 253-258. Kaşka, N., Küden, A.B., Küden, A., 1998. Performances of some local and foreign almond cultivars in South East Anatolia. Advanced Course. Production and Economics of Nut Corps. 18-29 May 1998, 1-5s, Adana.
Kaşka N, Küden AB, Küden A 1998. Performances of Some Local and Foreign Almond Cultivars in South East Anatolia. X GREMPA Seminar, Options Méditerranéennes, 33: 181-183

Küden AB, Küden A 2000. Badem Yetiştiriciliğii. TÜBİTAK - TARP Yayınları. Ankara, 18s.

Küden BA, Küden A, Bayazit S, Çömlekçioğlu S, İmrak B, Rehber Dikkaya Y 2014. Badem Yetiştiriciliği. TAGEP Proje No:5.2.3.1. Şeftali, Nektarin, Badem ve Elma Çeşit Adaptasyonu Projesi (KKTCGüzelyurt ve Türkmenköy Ekolojik Koşullarında Bazı Şeftali, Nektarin, Badem ve Elma Çeşitlerinin Meyve Verim ve Kalitesinin Saptanması). Okman Matbaası. Adana. 17s.

Lopes A, Matos A, Guine R 2016. Evaluation of Morphological and Physical Characteristics of Hazelnut Varieties. Millenium, -Journal of Education, Technologies, and Health 2(1): 13-24.

Mcguire RG 1992. Reporting of Objective Color Measurements. Hortscience 27: 1254-1255.

Melhaouia R, Addia M, Houmya N, Abida M, Mihamoua A, Serghini-Caida H, Sindicb M, Elamrania A 2018. Pomological Characterization of Main Almond Cultivars from the North Eastern Morocco. International Journal of Fruit Science. 110. DOI: $10.1080 / 15538362.2018 .1552232$

Milatovic D, Zec G, Durovic D, Boskov D 2017. Phenology of Flowering and Pomological Traits $f$ Almond Cultivars in the Region of Belgrade. Pomologia Croatica. Vol 21: 181-190.

Oğuz Hİ, Erdoğan Bayram S, Eroğul D 2011. Gap Üst Bölgesinde Kurak Koşullarda Yetiştirilen Standart Badem (Prunus amygdalus Batsch.) Çeşitlerinde Biyokimyasal ve Yağ Asitleri Kompozisyonlarının Belirlenmesi Üzerine Bir Araştırma. GAP VI. Tarım Kongresi, 09-12 Mayıs.

Şen SM, Karadeniz T 2015. The Nutritional Value of Walnut. Journal of Hygienic Engineering and Design, 11: 68-71.

Şimsek M 2016. Chemical, Mineral and Fatty Acid Compositions of Various Types of Walnut (Juglans regia L.) in Turkey. Bulgarian Chemical Communication, 48: 66-70.

Valverde M, Madrid R, Garcia AL 2006. Effect of the Irrigation Regime, Type of Fertilization, and Culture Year on the Physical Properties of Almond (cv. Guara). Journal of Food Engineering 76: 584593. 